The OT Interval in Lichtning Injury with

\title{
$N 91-32621$.
}

Implications for the 'Cessation of Metabolism' Bypothesis

by

Dr. Christopher J. Andrewg12 BE MEngSc DipCompSc MBBS MACS SMIEEE SMIREE

Dr. David M. Colquhoun! MBBS FRACP

Prof. Mat Darveniza2 BE PhD DEng FIEAust FIEEE FTS

The Wealey Hospital, Brisbane, Auntralia

2University of Queensland, St Lucia, Brisbane, Australia

\section{ABSTRACT}

An hypothesis is presented to provide an alternative explanation to the 'Cessation of Metabolism' hypothesis often invoked in lightning injury. 'Cessation of Metabolism' has been proposed to explain the observation of good recovery after a prolonged period in cardiac arrest in some lightning injured patients. Re-evaluation of ECGs from lightning injured patients which demonstrates a high incidence of QT prolongation. Re-examination of the cases used to support 'Cessation of Metabolism' also reveals little evidence to justify the hypothesis.

The finding of QT prolongation coupled with the hyperadrenergic state said to exist in lightning injury, may promote a state of episodic induction of and recovery from Torsade de Pointes Ventricular Tachycardia (VT). Histological examination of the myocardium supports the new hypothesis.

This is the first concerted description of lightning injury as one of the general causes of QT prolongation. It appears to occur frequently after lightning injury, is a prerequisite of and predisposes to episodes of Torsade de Pointes VT. These electrocardiographic abnormalities explain 'Cessation of Metabolism' and recognition may change management and lead to greater survival.

\subsection{Introduction}

Reported survival after lightning strike following prolonged periods of unresuscitated cardiac arrest remains enigmatic.

In re-appraising the literature containing these reports, the authors have noted that a large number of electrocardiograms in reports of lightning injury demonstrate a prolonged QT interval. This prolongation has only been noted in passing previously and/or in isolated cases (e.g. Divakov (1966), Palmes (1987)). The authors draw together the literature on electrocardiograms of lightning injured patients and provide the first unified collation of QT prolongation.

There is general consensus in the cardiology literature that a prolonged QT interval is a prerequisite for the development of Torsade de Pointe ventricular tachycardia (VT). In this paper, the implication of this fact for lightning injury is explored, and it is proposed that it is possible that longer than normal periods of apparent arrest are explicable using a Torsade model.

In acute hyperadrenergic states reversible severe cardiac failure resulting in acute pulmonary oedema can occur. This is seen, for example, in Scorpion, jelly-fish an Irukandji stings (Guerow (1980), Williamson (1988)). In the chronic hyperadrenergic state such as exists in phaeochromocytoma, a reversible cardiomyopathy may occur (Velasquez (1984)). Myocardial biopsy shows patchy myocardial necrosis. In lightning injury pulmonary oedema may occur, patchy myocardial necrosis has been documented, and a hyperadrenergic state is probably the norm, though likely of severe intensity but brief duration.

Lastly, it is noted that Torsade VT may occur as a paroxysmal entity and during its process an individual may appear to be in cardiac arrest.

These issues are expanded in succeeding sections and a final hypothesis is proposed. 


\subsection{Elements from the Literature}

One of the major enigmas of lightning jnjury is the widely claimed phenomenon of documented survival with minimal deficit after prolonged unresuscitated cardiac arrest. This contention appears untenable, and flies in the face of accepted findings where it is agreed that cerebral anoxia leads to permanent damage after four minutes of lost perfusion.

To explain this it has been proposed that, after a strike, all metabolism ceases and that the lack of metabolic demand means lack of perfusion is immaterial. This proposition receives most currency due to its espousal by Taussig (1968). Since then it has often been repeated (e.g. Nesmith (1971), Bartholome, et al., (1975), Msonge, et al., (1976), Kleiner, et al.,(1978)). Although the notion is widely attributed to Taussig, in fact it predates her widely quoted paper though not in such definite form. Former reports include those of Critchley(1934), Jellinek(1942), and Ravitch, et al.,(1961).

Jex-Blake(1913) provides a fascinating account of the history of views on lighining injury which include views on resuscitation. Many are obviously speculative, but an equivalent of cessation of metabolism does not seem to have been mentioned to that stage. The first time that the proposal is made is attributed by Critchley(1934) to Jellinek(1932a and 1932b). The effect is described in this initial work as 'suspended animation'. The notion that respiration and circulation were intimately involved with survival had long been current (see Jex-Blake), and the necessity to re-egtablish both was known. Critchley(1934) was the Grst to suggest that resuscitation after 'several hours ${ }^{2}$ of demonstrated cessation of respiration and circulation was possible, based not on personal experience but on other reports. The reason for the resucitability was said to be that the victim was in 'suspended animation'. Lynch and Shorthouse(1949) provide a similar reference to Jellinek and Critchley, and are perhaps the first to pronounce scepticism over the phenomenon saying that a certain German expert Alvensleben was sceptical over resuscitation after more than half an hours 'suspended animation'. Nonetheless they recognise that reports of long term suspended animation being reversed exist - but more often after technical electrical injury than lightning injury.

Ravitch, et al.,(1961), also summarised earlier by Morikawa, et al.,(1960), provide a report of such a case. A child was struck and immediately after the strike was questionably thought to demonstrate a pulse, but no respiratory effort. He was given manual respiration for about 10 minutes, and this was then ceased though a pulse was still thought possibly to be present. Seven minutes later he arrived at hospital by ambulance with no successful pulmonary inflation for all that time and was found to be pulseless. An open thoracotomy indicated an asystolic heart with no bleeding from the wound. After a further three minutes - 20 minutes from the strike cardiac action was restored, and ultimately successful restoration of function was achieved.

This sequence of events was later cited by Taussig(1968) as her only support for the hypothesis of immediate 'cessation of metabolism' in lightning strike thus allowing prolonged arrest with successful later resuscitation. The example is therefore not a good one in this connection. It would seem more to fit the sequence of events described by Andrews et al.,(1989a) in which experimental data supported the hypothesis of primary cardiac arrest and respiratory arrest, followed by cardiac recovery and secondary hypoxic arrest.

Based only on the case above, Taussig strongly asserts that all body metabolism ceases after a lightning strike. The assertion has then been repeated by several authors in a form giving it status as accepted theory.

There is no experimental evidence to support the contention of cessation of metabolism and it is seriously questioned by those with any experience in treating such patients (Cooper (1989), ten Duis (1989), Andrews, et al., (1989b)).

Several reports commonly regarded as supporting the notion of such recovery (see e.g. Kleiner, et al.,(1978) who state that at least 6 published cases support the contention) bear further examination, e.g. Kravitz, et al.,(1977), Kleinot, et al.,(1966), Yost, et al.,(1974), Burda(1966), Hanson, et al.,(1973). In each of these cases there was certainly a prolonged period of cardiac arrest, but early resuscitation was also attempted to greater or lesser degree within the knowledge of the day. Most often this was respiratory 
support only. In the given reports, there was no documented period of prolonged hypoperfusion that would require the induction of an hypothesis to suggest low metabolic demand. The fact that recovery was achieved, at least temporarily, indicates more the success of the resuscitation attempted. It may be that such resuscitation was ineffective, given more recent knowledge of techniques of emergency first aid, and, if so, one must look for further explanation for the documented survival, but the reports concerned are not couched in this light. That another explanation is required is only necessary if it is presumed that ineffective attempted resuscitation occurred, and certainly not as a result of documented prolonged unresuscitated arrest. There is no evidence to support recovery from lightning injury after the accepted period of a small number of minutes of unresuscitated arrest has passed, and it is on this misconception that many of the claims for a state of metabolic standstill have been made.

Indeed, one of the present authors (Andrews, et al. 1989b) has stated that the 'cessation of metabolism' hypothesis though implausible has not been supplanted by anything better if indeed one accepts that the phenomenon occurs at all. Though evidence is at best questionnable, as above, for recovery after a documented prolonged unresuscitated arrest, the dogma is still widely held. At best, survival after prolonged unconsciousness with attempted resuscitation, is supported by the literature. It is the aim of the following discussion to propose a more plausible alternative than the currently held version of 'cessation of metabolism' on the assumption that resuscitation was less than effective given it was generally non-cardiac, and using techniques of respiratory support that have been supplanted.

\subsection{Torsade de Pointe Ventricular Tachycardia}

In developing a new hypothesis, we first discuss a recent strand of the cardiological literature.

Dessertenne (1966) identified a 'new' morphological form of ventricular tachycardia (VT). The initial recognition was based on morphological grounds alone. Cokkinos, et al., (1978), state that its characteristics are a changing pattern of ventricular complexes, -pontaneous onset and offeet, refractoriness to defibrillation and a number of antiarrhythmic drugs, especially quinidine and other Type I agents. They state that prior to induction of a paroxysm, QT prolongation is almost universally seen. They note distinct differences between the new form and classical VT:

i. The complexes are almost identical to each other rather than polymorphous, with undulation of the QRS axis over a series of 5-20 beats with concomitant alternation of size

ii. Classical VT (and indeed ventricular fibrillation (VF)) are seldom self limited, while spontaneous onset and offset is a hallmark of the new form

iii. Electroversion is of no help in the new form, and antiarrhythmic medication often exacerbates the arrhythmia.

Thus the morphological appearance of the arrhythmia is of an undulant series of similar appearance ventricular complexes twisting in axis around the electrical baseline giving the appearance of a modulated sine wave. The descriptive term 'Les Torsade de Pointes', or roughly translated, 'the twisting of the points', was coined by the French writers initially describing the arrhythmia. Other descriptive terms have been applied, with varying degrees of correctness - 'cardiac ballet', 'paroxysmal ventricular fibrillation', 'transient recurrent ventricular fibrillation', and 'polymorphic ventricular tachytachycardia'.

Clinical features of Torsade include an episodic course with dramatic drop in (but not absence of) cardiac output during an episode, and consequent syncope. Historical features may include, among others, antiarrhythmic drug ingestion (especially Type I), phenothiazine ingestion (especially thioridazine), a family history of one of the hereditory QT prolongation syndromes, an associated hypokalaemia, and usually QT prolongation. Thus impaired repolarisation, for one of many reasons, is a cardinal feature of the arrhythmia. It is specifically predisposed, also, in situations of bradycardia or high grade AV block, and can degenerate into VF or VT or remain episodic.

The onset of Torsade seems to be due to an extrasystole occurring late in the $T$ wave, as opposed to classical VT or VF where the extrasystole occurs early in the critical interval. Krikler, et al., (1976) use this 
observation, and the fact that they have seen Torsade induced in several cases by electrical stimulation, to suppose that it is due to a re-entry mechanism in a setting of impaired repolarisation.

The underlying pathophysiology is only postulated at this stage but a consensus view seems to be that it represents two (or more) ectopic foci operating slightly out of synchrony with the ventricles attempting to synchronise first with one, and then the other, focus. The synchronicity is thought to be variable in extent, and gradually changing between the two foci. Other explanations have been given, and Kossman, (1978), for example, provides a good summary of these and an attempt to place Torsade into a classification of atypical ventricular arrhythmias.

For our purpose it is noted that a lightning strike could indeed represent the electrical stimulation required as above, and that the cardiac insult suffered could indeed impair repolarisation by disruption of membrane pores and pumps. Thus a situation predisposing to episodic arrhythmiae could indeed be set up.

The next section examines evidence for impaired repolarisation after lightning strike.

\subsection{The QT Interval in Lightning Strike}

Palmer(1987) has noted a prolonged QT interval in the ECG of a patient following lightning strike. In this patient $Q T$ prolongation was initially slight, and increased over several days and then resolved over a period up to one month. Cheng(1988) contends this may have been pseudo-prolongation, but admits that the consequences for possible arrythmias are the same. Kleiner, et al.,(1978) note QT prolongation in passing in a short review, and Divakov(1966) is said to note similar prolongation, though a translation of that work is not available to the present authors. Generally QT prolongation has passed untecognised.

$A$ re-examination of ECG tracings in published literature known to the authors (that is in the bibliography in Andrews, et al., (1989b), supplemented to date) has been undertaken and the QT interval in each tracing has been measured. This is presented in Table 1 where rate corrected QT intervals are then compared with the 'normal' value of $440 \mathrm{mS}$.
When those cases in which a definite $\mathrm{QT}_{\mathrm{c}}$ can be determined are examined, it will be seen that $64 \%$ demonstrate a prolonged $\mathrm{QT}_{\mathrm{c}}$. Only $33 \%$ show a normal $\mathrm{QT}_{c}$, and of these the shortening is relatively little, compared with a dramatic degree of lengthening in the other cases. The only problem with a compilation such as this is that in a percentage of reported cases, a full tracing is not given (only isolated complexes are shown), and thus heart rate is not able to be found.

In an attempt to include those cases where a heart rate was not obtainable, the $\mathrm{QT}_{c}$ has been determined assuming a heart rate of $50 \mathrm{~min}^{-1}$. This is highly conservative, and if the QT interval is long at this rate, it will certainly be long at a (more likely) higher rate. For those with assumed heart of $50 \mathrm{~min}^{-1}$ $59 \%$ demonstrate a long $\mathrm{QT}_{c}$, and only $37 \%$ are normal. Again the same observation as above regarding the shorter intervals holds. Of course, no account has been taken of a normal range of $Q T_{c}$, with the above figures derived on a strict application of a normal value of $440 \mathrm{mS}$.

It may be seen, then, that the vast majority of tracings show QT prolongation, and the general tendency is for QT interval to extend during a recovery phase after injury. Often a period of some months elapses before normality returns. The time course of $Q T_{c}$ prolongation is shown when the results are graphically presented against their time course in Fig. 1. In this figure both stated rate and assumed rate $\left(50 \mathrm{~min}^{-1}\right)$ measurements are shown and a distinct appreciation of the time course of recovery can be seen. This reinforces the view that in lightning injury cardiovascular followup should extend for a substantial period after recovery is otherwise thought to have been effected.

\subsection{Myocardial Necrosis and Hyperadrenergia in Lightning Strike}

The next theme to be taken up is that of the histopathological findings in lightning injury within the myocardium. The picture is somewhat variable, and only those victims actually succumbing to their injuries have histological study of their myocardium performed. Necrosis in some form is however the rule. No myocardial biopsies have been done on survivors of lightning strike.

Hanson, et al.,(1973) present two cases where defined localised areas of necrosis of the 
posterior wall of the myocardium was found. Increased serum catecholamine levels ante-mortem (dominantly adrenaline) were also demonstrated. The findings in the case reported by Ekoe, et al.,(1985) were of a larger inferior area of necrosis and in both these reports, the picture was of a coagulative necrosis with diffuse (patchy) inflammatory infiltration. Myers, et al.,(1977) report a localised large inferior infarction but with no comment on histology.

Kotogal, et al.,(1982), however, report a different picture. After treatment for seven days in which there were also several periods of ventricular tachycardia, the patient died and myocardial histology showed diffuse varying stages of myocardial necrosis. Wakasugi, et al.,(1986) report a similar picture. Kravitz, et al.,(1977) describe a case in which diffuse myocardial necrosis was found, and also a hyperadrenergic state was demonstrated. It was commented that "the most prominent findings were the focal myocardial necrosis, myocardial degeneration, and early reorganization of myocardial loss with fibroblastic replacement".

The case reported by Chia(1981) is of interest. It is a case demonstrating pulmonary oedema (see below), and unfortunately no comment is made regarding measurement of catecholamines or QT prolongation.

McCrady-Kahn, et al.,(1981) report the transient hypertension and tachycardia often seen and note normal urinary catecholamines. No other cause for the signs could be found, and serum catecholamines were not measured.

While not a universal picture, it may be said that there is a body of reports which notes patchy myocardial necrosis, and elevated serum catecholamines. Pulmonary oedema is also seen (Buechner, et al.,(1961), Kleiner, et al.,(1978)), and the author's personal evaluation of local post-mortem reports (Andrews, unpublished data) shows a $70 \%$ incidence of pulmonary congestion in the 10 victims examined.

\subsection{Pulmonary Oedema and Myocardial} Necrovis in Phaeochromocytoma

A recent report of cases of otherwise unexplained cardiac failure (Sardesai, et al.,(1990)) draws attention to the fact that phaeochromocytoma can produce a cardiomyopathy, and this can lead to pulmonary oedema and cardiac failure. As it may not readily come to mind, they argue for its inclusion on any differential diagnosis of otherwise unexplained pulmonary oedema. Further it is argued that normal urinary catecholamine levels do not exclude the diagnosis. The histological picture seen is one of patchy myocardial necrosis. It is stated by the authors that this picture is "consistent and predominant".

\subsection{An Alternative Hypothesis to Cessation of Metabolism}

A synthesis of the above elements is possible. Admittedly this synthesis is speculative, however it is believed plausibly so - more so than alternatives. The wide currency of the questionnable 'cessation of metabolism' alternative requires a more plausible alternative explanation, even though there is slight evidence to encourage one to delay resuscitation as a desirable course. Indeed the opposite. The hypothesis detailed below is thought to be operative also where pulmonary resuscitation alone is given in a state of prolonged arrest. The occurrence of this state does have support from the literature (indeed, wide support), and demands examination.

It is first noted that Andrews et al. (1989a) have given credence to a form of the secondary arrest dogma. They showed that the initial arrest after lightning injury is likely to be asystolic, and that the heart restarts in a brief period of bradycardia. After two to three bradycardic beats, an intense tachycardia is evidenced, and the heart proceeds to secondary hypoxic arrest as a result of continuing respiratory arrest. The tachycardia was taken as indication of hyper-adrenergia, though this is not always demonstrated in reported cases. Thus adrenergic stimulation must be regarded, at best, as variable in the injury.

A hypothesis of subsequent cardiac behaviour is now outlined especially where some form of respiratory support has been given.

It is first noted that QT prolongation highly predisposes to Torsade de Pointe V'T and that QT prolongation is a strong feature of lightning injury. In that state, pulses will be absent. A victin will therefore appear to be in cardiac arrest. Nonetheless it is known that cardiac output may still be just present in this or indeed other forms of V'T, though not of course compatible with anywhere near full 
function.

Subsequent events, it is postulated depend on catecholamine levels in the individual case.

If it is assumed that a hyperadrenergic state exists, then Torsade VT may well terminate in cardiac recovery, at least initially. Sufficient catecholamine may arrive at the heart to stimulate recovery, and a good rhythm and output may occur and be maintained. If sufficient catecholamine levels persist the heart may proceed to secondary hypoxic arrest as outlined above. It is concievable that if catecholamine levels fall subsequent to this degree of recovery, further episodes of Torsade VT may then occur and the process may cycle.

Alternatively, if catecholamine levels are not high, the heart may again lapse into bradycardia and/or episodic Torsade VT, since QT prolongation will still exist. Episodes of Torsade VT and bradycardia may be sufficient to maintain perfusion just sufficient to maintain viability.

In either case, and the balance may depend on catecholamine levels in individual cases, and a period relatively longer than the classically allowed few minutes in cardiac arrest will appear to have occurred. The victim may appear pulseless and lifeless as if cardiac arrest due to ventricular fibrillation has occurred. If ventilation without cardiac support occurs, as has been reported in the literature especially in days prior to external cardiac compression, then the state may persist for some time giving an illusion of recovery after prolonged arrest.

Further support for the presence of circulating catecholamines is gained from the histological picture of the myocardium at autopsy mirroring that in phaeochromocytoma. While not at all the only explanation for patchy necrosis, at least it may be one factor.

Recent experimental work (Factor et al. (1985)) has demonstrated that high levels of catecholamines may precipitate vascular spasm and medial smooth muscle contraction bands (MSC) (Ming, et al., (1976), Van Citters, et al. (1962), Joris, et al. (1981)). Histological examination of coronary arteries of patients who had premorbid conditions associated with high levels of catecholamines showed a high frequencies of MSC. This suggests coronary artery spasm may be frequent in hyperadrenergic states. The subsequent myocardial ischaemia predisposes to ventricular arrhythmias including Torsades de Pointes. Catecholamine release can be a cause or trigger for the development of Torsades de Pointes VT.

Thus an alternative hypothesis to 'Cessation of Metabolism' has been proposed, its operation depending on catecholamine levels, and enhanced by varying degrees of artificial ventilation.

\subsection{References}

Andrews, C.J., and Darveniza, M., (1989a), "Effects of Lightning on Mammalian Tissue", Proc. Third Int. Conf. Lightn. Stat. Elec., Bath Sept. 1989, ERA Tech., Leatherhead, Surrey.

Andrews,C.J., Darveniza,M., and Mackerras,D., (1989b) "Lightning Injury: $A$ Review of Clinical Aspects, Pathophysiology, and Treatment", Adv. Trauma, 4:241-288, 1989.

Bartholome, C.W., Jacoby, D., and Ramchand, S., "Cutaneous Manifestations of Lightning Injury", Arch. Dermatol, 111:1466-8, 1975.

Buechner, H.A., and Rothbaum, J.C., "Lightning Stroke Injury - A Report of Multiple Casualties from a Single Lightning Bolt", Milit.Med., 126:775, 1961.

Burda, C.A., "Electrocardiographic Changes in Lightning Stroke", Am. Heart.J., 72:521, 1966.

Cheng, T.O.,"Lightning . Injury Causing Prolongation of the QT Interval", Postgrad. Med. J., 64:335, 1988.

Chia, B.L., "Electrocardiographic Abnormalities and Congestive Cardiac Failure due to Lightning Stroke", Cardiol., 68:49-53, 1981 .

Clore, E.R., and House, M.A., "Prevention and Treatment of Lightning Injuries", Nurs. Pract., 12(12):37-45, 1987.

Cokkinos,D.V., Mallios,C., Philias,N., and Vorides,E.M., " 'Torsade de Pointe': A Distinct Entity of Ventricular Arrhytmia?", Acta Cardiol., XXXIII(3):167-84, 1978. 
Cooper, M.A., Personal Communication.

Craig, S.R. "When lightning strikes. Pathophysiology and treatment of lightning injuries", Postgrad Med, 79(4):109-12, 121-4, 1986.

Critchley, M., "Neurological Effects of Lightning and of Electricity", Lancet, 1:68, 1934.

Dessertenne,F., "La Tachycardie Ventriculaire a Deux Foyers Oppose Variables", Arch. des Mal du Coeur, 59(2): 263-72, 1966

Divakov, G.M., "ECG Changes in Persons Struck by Lightning (title trans from Russian)", Klin. Meditsima (Mosc.), 1966, 95.

du Pasquier,G., and Freeman,J., "Le foudroiement", Ann. Fr. Anesth. Reanim., $5: 601-4,1986$.

du Toit, J.S., "A Case of Bilateral Cataract Caused by Lightning", J. Med. Soc. S. Afr., 1:503, 1927.

Eber,B., Himmel,G., Schubert,B., et al., "Myokardiale Schaedigung nach Blitzschlag", Z. Kardiol., 78:402-4, 1989.

Ekoe, J.M., Cunningham, M., Jacques, O., et al., "Disseminated Intravascular Coagulation and Acute Myocardial Necrosis caused by Lightning", Int.Care.Med, 11:160, 1985.

Factor, S.M., and Cho, S., "Smooth Muscle Contraction Bands in th Media of Coronary Arteries: $A$ Posrmortem Marker of Antemortem Coronary Spasm", JACC, 6(6):1329-37, 1985.

Funiak,S., Hendrich,F., Drimal,J., Markuljak,I., and Funiakova, S., "Srdcovy Infarkt Pri Poraneni Bleskom", Vnitrni lekarstyi, 30(11):1118-21,1984.

Guerow, M., Grupp, R.J., Gabel, M., Grupp,G., "Hemodynomic and Myocardial consequences of Scorpion Venom", Am. J. Cardiol., 45:979, 1980.

Gupta,G.B., Gupta,S.R., Somani,P.N., and Agrawal,B.V., "Atrial Fibrillation with Inferior Wall Myocardial Ischaemia Following
Lightning", J. Assoc. Phys. India, $36(5): 354-5,1988$.

Hansen, G.C., and Mcllwraith, G.R., "Lightning Injury: Two Case Histories and a Review of Management", Brit Med J., 4:271, 1973.

Jackson, S.H.D., and Parry, D.J., "Lightning and the Heart", Br. Heart. J., 43:454, 1980.

Jellinek,S., Wien Klin Wschr., 45:37, 1932a, quoted in Lynch, et al., op cit.

Jellinek,S., Electrische Verletzungen, Leipzig, 1932b, quoted in Lynch, et al., op cit.

Jellinek, S., "Death by Lightning (Letter)", Brit. Med. J, Dec. 12, 1942, p714.

Jex-Blake, A.J., "Goulstonian Lectures: Death by Electric Currents and by Lightning", Brit. Med. J, pp 425-430, 492-498, 548-552, $601-603 ;$ Mar. 1, 8, 15, 22, 1913.

Joris, 1., and Majno, G., "Medial Changes in Arterial Spasm Induced by L-Norepinephrine", Am. J. Pathal., 105:212-22, 1981

Kleiner, J.P. and Wilkin, J.H., "Cordiac Effects of Lightning Stroke", JAMA, 240:2757, 1978.

Kleinot, S., Klachki, D.M., and Keeley, K.J., "The Cardiac Effects of Lightning Injury", S.Afr.Med.J., 40:1141, 1966.

Kossman,C.E., "Torsade de Pointes: An Addition to the Nosography of Ventricular Tachycardia", editorial, Am.J.Cardiol, 42:1054-6, 1978 .

Kotogal, S., Rawlings, C. A., Chen, S., Burris, G., and Nouri, S., "Neurologic, Psychiatric and Cardiovascular Complications in Children Struck by Lightring", Paed., 70(2): 190, 198'2.

Kravitz, H., Wasserman, M.J., Valaitis, J., et al. "Lightning Injury", Am. J. Dis. Child., $131: 413,1977$.

Krikler,D.M., and Curry,P.V.L., "Torsade de Pointes, an Atypical Ventricular Tachycardia", Br. Heart J., 38:117-20, 1976. 
Kroob, M.J., and Cram, A.E., "Lightning Injuries: A Multisystem Trauma", J. Iowa. Med. Soc., 73(6): 221, 1983.

Lynch, M., and Shorthouse, P.H., "Injuries and Death from Lightning", Lancet, 1:473, 1949.

Morikawa, S., and Steichen, F., "Successful Resuscitation after 'Death' from Lightning". Anesthesiol., 21(2):222-4, 1960.

Ming, S-C, McNiff, J., "Acute Ischemic Changes in Intestinal Muscularisis", Am. J. Pathol., 82:315-26, 1976

Msonge, B., and Evans, R.L., "Lightning Stroke on Ukerewe Island", East Afr. Med. J. 53(6):350-1. 1976.

Myers, G.J., Colgan, M.T., and van Dyke, D.H., "Lightning Disaster Among Children", JAMA, 238:1045, 1977.

Nesmith, M.A., "A Case of Lightning Stroke", J. Fla. Med. Assn., 58:36, 1971, quoted in Hanson, et al.,(1973).

Palmer, A.B.D., "Lightning Injury cousing prolongation of the $Q-T$ internal", Post. Med. J., 63-891-4, 1987.

Ravitch, M.M., Lane, R., Safar, P., Steichen, $F$., and Knowles, P., "Lightning Stroke", NEJM, 264(1): 36, 1961.

Read, J.M. "Man Struck by Lightning Reveals Marked ECG Changes Hours Later", Med. Trib., March 28, 1966, p3.

Sardesai,S.H., Mourant,A.J., Sivathandon,Y., Farrow,R., Gibbons,D.O., "Cardiomyopathy Presenting as Heart Failure", Brit. Med J., 1990.

Schmidt, W., Gruetzner,A., and Schoen,H.R., "Beobachtungen bei Blitzschlagverletzungen unter Beruecksichtigung von EKG and $E E G^{\prime \prime}$, Deutsches Arch. Klin. Med., 204:307-24, 1957.

Sinha, A.K., "Lightning Induced Myocardial Injury - A Case Report With Management", Angiol, 36(5):327, 1985.

Taussig, H., "'Death' from lightning and the
Possibility of Living Again", Ann.Int.Med, 68:1345, 1968.

ten Duis,H.J., Personal Communication.

Terranova,S., "Su un Caso di Infarto Miocardico da Elettrocuzione Atmosferica", Rif. Med., 71(4):93-96,1957.

Van Citters, R.L., Wagner, B.M., Rushmer, R.F., "Architecture of Small Arteries During Vasoconstriction", Circ. Res., 10:668-75, 1962.

Velasquez,G., O'Souza, V.J., Hackshaw, B.T., Glass, T.A., et al.,

"Phaeochromocytoma and cardiomyopathy", Br. J. Radiol., 57:89, 1984.

Wakasugi, C., and Masui,M., "Secondary Brain Hemorrhages Associated with Lightning Stroke: Report of a Case", Jpn. J. Legal Med., $40(1): 42-6,1986$.

Williamson,J.A., Burnett, J.W., Colquhoun, D., et al., "The 'Irukandji Syndrome' and Acute Pulmonary Oedema", Med. J. Aust., 149:150-156, 1988.

Yost, J.W., and Holmes, F.F., "Myoglobinuria Following Lightning Stroke", JAMA, 228:1147, 1974.

Zeana, C.D., "Acute Transient Myocardial Ischaemia After Lightning Injury", Int.J.Cardiol., 5:207, 1984. 
TABLE 1 QT Interval measurements

derived from the Lightning Literature

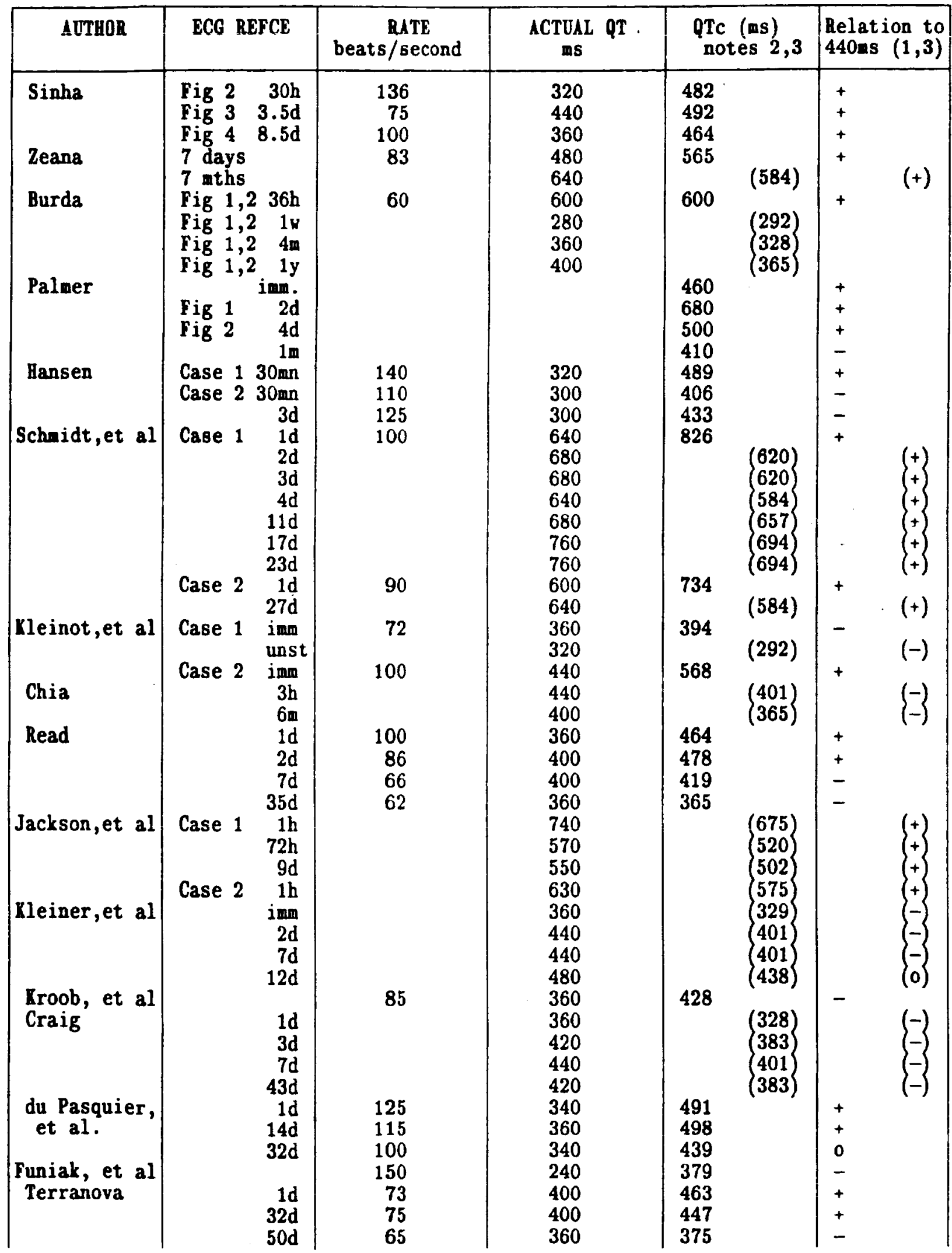




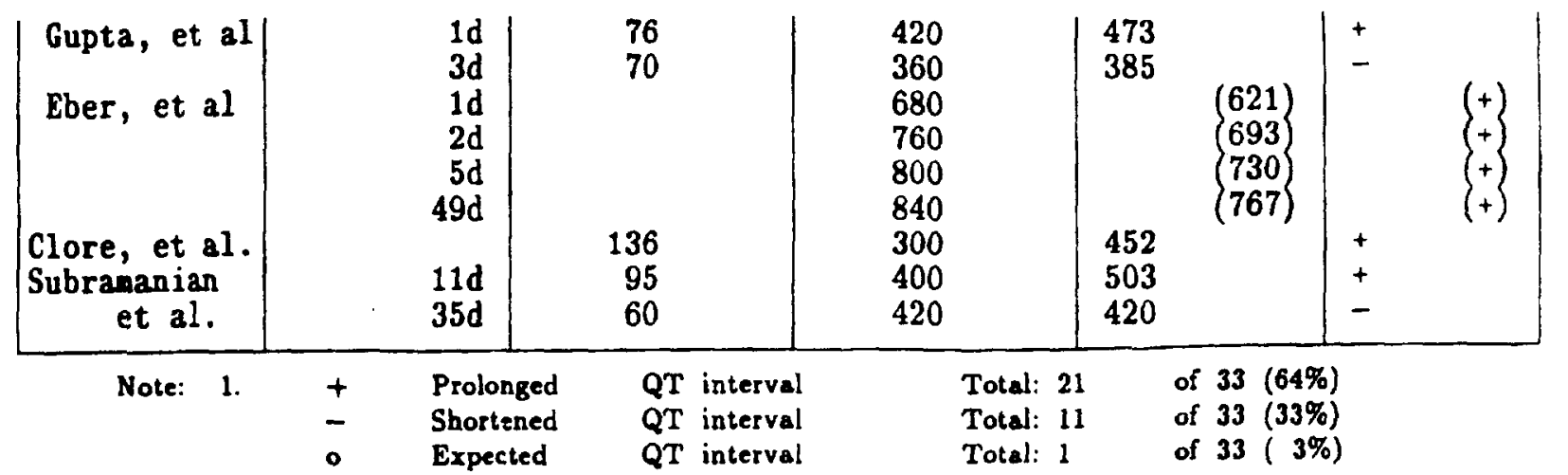

2. Formula of Bazzett $\mathrm{QT}_{c}=\mathrm{QT}_{\text {measured }} / \sqrt{\mathrm{RR} \text { interval }}$

3. Figures in parenthesen represent $\mathrm{QT}_{c}$ based on rate of $50 \mathrm{~min}^{-1}$, where no rate wa given in text. This is a coneervative seaumption. If $Q T_{c}$ is long at this rate, it will certainly be long at a bigher rate
(t) Posaibly long $\mathrm{QT}_{\mathrm{c}}$
Total: 16
of $27(59 \%)$
(-) Short QT $\mathrm{C}$
Total: 10
of $27(37 \%)$
(o) Expected QT
Total: 1
of $27(4 \%)$ 


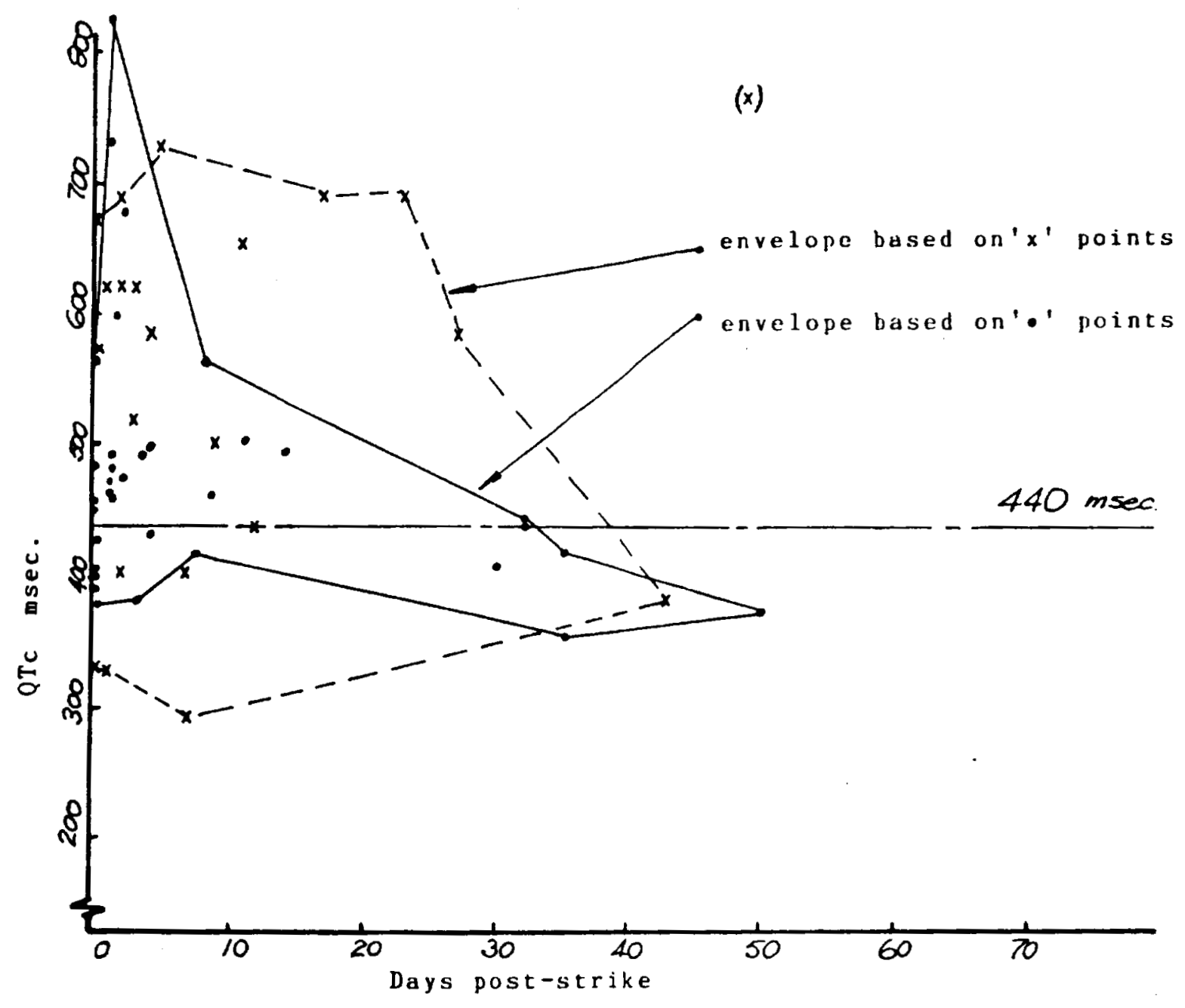

Fig.1. QTc vs time for lightning injured patients. ( ( ) based on rate derived from report 